\title{
Los derechos económicos, sociales y culturales de los pueblos indígenas del Perú en el marco del reconocimiento de su dignidad e identidad cultural Luis Alberto del Castillo Soria * http://dx.doi.org/10.21503/lex.v10i9.325
}

Candidato a doctor en Derecho en el Programa de Derechos Fundamentales, con Diploma de Estudios Avanzados (DEA) en Derecho Internacional de los Derechos Humanos por la Universidad Carlos III de Madrid (España). Consultor del Instituto de Estudios Amazónicos Regionales (IDEAR). Procurador, de la "Procuraduría Pública Especializada en asuntos Jurídicos del Ministerio del Interior”.

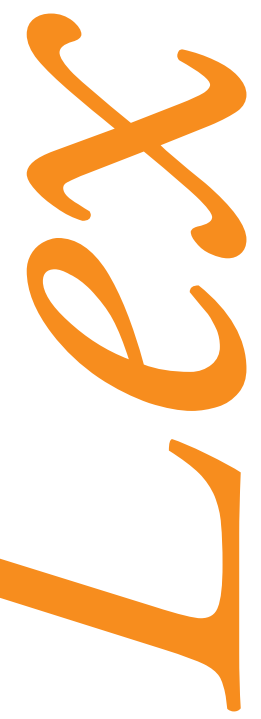




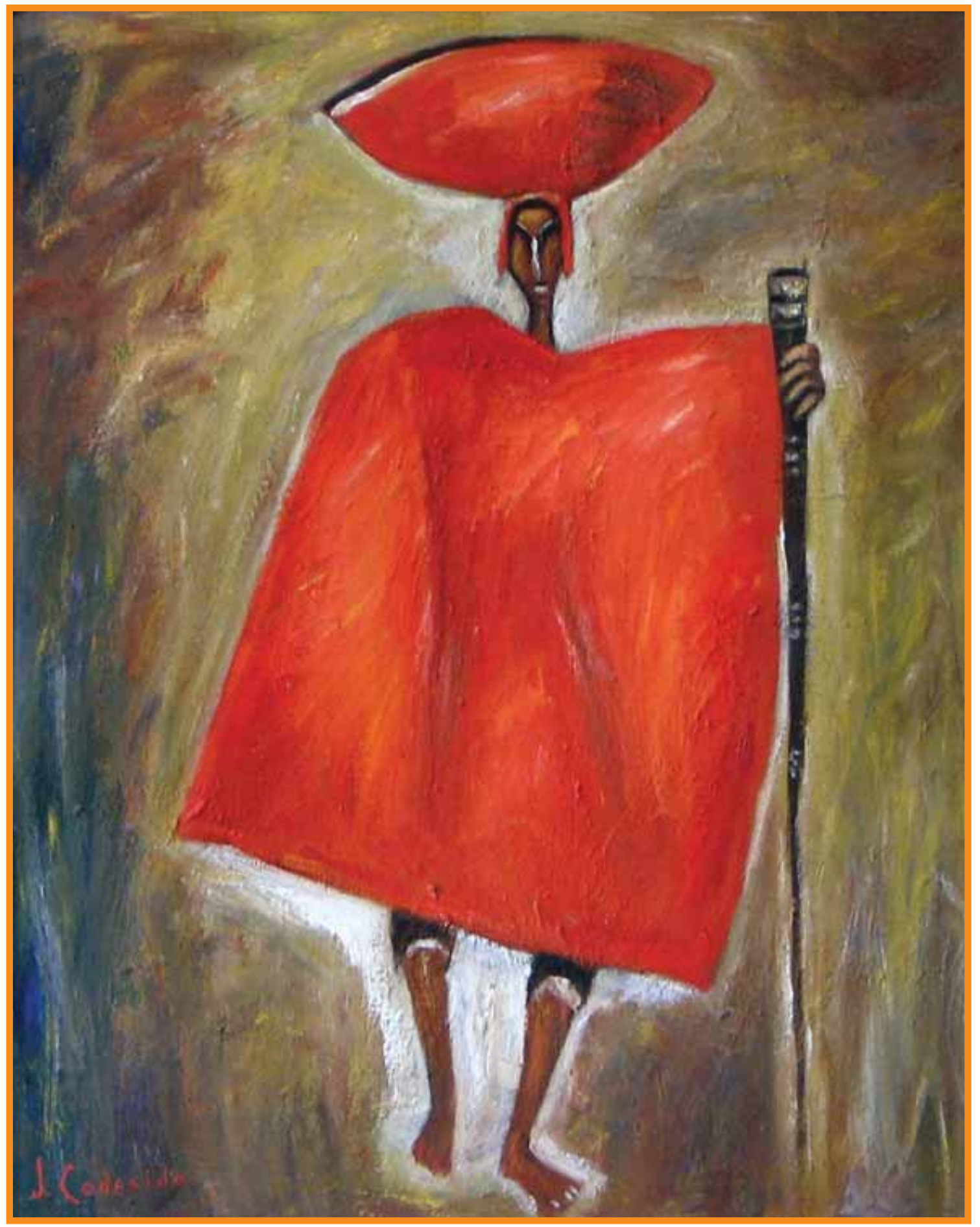

El Varayoc. Colección BBVA Banco Continental. 


\section{INTRODUCCIÓN}

Es relevante abordar los derechos humanos de los pueblos indígenas en un contexto de evidente evolución del concepto de los derechos y de expansión de los sistemas de protección internacional y nacional de los derechos humanos en el mundo, pero, específicamente, de falta de reconocimiento y mecanismos efectivos que garanticen los derechos de los pueblos indígenas tanto en el marco del Derecho Internacional como dentro de la normativa de los Estados, hecho que constituye una forma más de vulneración de sus derechos económicos, sociales y culturales.

Es necesaria y central, pues, una reflexión jurídica y práctica en torno a tres puntos básicos:

1. En primer lugar, el debate de los derechos humanos de los pueblos indígenas como un reconocimiento de su identidad cultural y como un derecho social, en el marco del reconocimiento de los derechos económicos sociales y culturales. Se debe además considerar a toda cultura como culta, y promover tanto el respeto de una cultura para con la otra como la creatividad que genera la interrelación de culturas distintas que producen nuevas manifestaciones originales.

2. La situación actual de los derechos económicos, sociales y culturales de los indígenas en el contexto internacional y particularmente en el caso del Perú, que nos permita identificar los aspectos relevantes, desencuentros y contradicciones, más allá de la Ley de la Consulta Previa ${ }^{1}$.

3. La perspectiva de los derechos humanos de los pueblos indígenas que exprese avances hacia nuevas formas de relación entre el Estado, la sociedad y los pueblos indígenas.

El interés actual del debate en torno a este tema se debe a múltiples factores, siendo dos los que mayormente han impulsado su desarrollo a nivel internacional:

\footnotetext{
Esta Ley incorpora a la legislación nacional un derecho ya reconocido en el DERECHO INTERNACIONAL de los derechos humanos, y en este sentido, constituye un avance significativo en la defensa de los derechos humanos de los pueblos indígenas en el país.
} 
- La propia preocupación de los pueblos indígenas por fortalecer y recuperar su identidad, como necesidad y decisión de sobrevivir como pueblos.

- Los cambios que presenciamos a nivel mundial en el área de los derechos humanos.

El proceso de globalización de los derechos humanos no podía excluir el tema de los derechos de los pueblos indígenas, surgiendo una preocupación de las organizaciones internacionales en el tema. Los grandes problemas humanos, sociales y políticos en el mundo han afectado la vida de los pueblos indígenas como resultado de los cambios producidos. Ante estos hechos, surge la necesidad de impulsar la difusión de la realidad de los pueblos indígenas, el valor que ellos han aportado al patrimonio mundial y el respeto de sus derechos colectivos e individuales.

En el presente siglo, ante el fenómeno de la interdependencia e intercambios continentales, la mundialización de la información y los mercados, se ha generado una globalización asimétrica y centrista que plantea a los pueblos y naciones transformaciones en función de estas exigencias. La fuerza de este ordenamiento internacional difícilmente incluye lo distinto, como si lo diferente estuviera aparentemente condenado a desaparecer.

El presente ensayo enfocará los tres puntos básicos arriba señalados, con el objetivo de reafirmar el reconocimiento de la otredad, como fuerza que supere el etnocentrismo cultural, posibilitando el derecho y la afirmación de la diferencia, que haya podido transitar del reconocimiento del YO individual al NOSOTROS y mostrar las acciones que a nivel internacional vienen fortaleciendo el planteamiento de la interculturalidad como una posibilidad de fecundación mutua entre los diferentes pueblos y culturas que comparten espacios en los cuales desarrollan sus planes de vida, superando el exclusivismo cultural y la marginación social, y que a partir de esfuerzos conjuntos este presente siglo ofrezca un panorama nuevo para millones de indígenas.

\section{LOS DERECHOS ECONÓMICOS, SOCIALES Y CULTURALES DE LOS PUEBLOS INDÍGENAS DEL PERÚ}

\subsection{Evolución histórica de los derechos económicos, sociales y culturales}

El Derecho Constitucional está íntimamente ligado al origen y evolución histórica de los derechos humanos, cuya incorporación a la historia del constitucionalismo se da con los llamados derechos humanos de primera generación, los mismos que tienen su origen en los procesos constitucionales provocados por la Revolución Americana de 1776 y la Revolución Francesa de 1769. Con ellos se universalizan los principios de libertad e igualdad individual, así como la garantía de los derechos esenciales de la persona humana en el mundo. 
Durante la crisis del Estado liberal en el siglo XIX, con la aparición del capitalismo industrial, se ponen en cuestión los clásicos derechos individuales ante las nuevas demandas de derechos económicos, sociales y culturales. A partir de entonces, surgen los derechos humanos de segunda generación o derechos humanos del constitucionalismo social, ${ }^{2}$ los cuales se empiezan a incorporar en las Constituciones de Francia de 1848, de la URSS de 1918 y 1936, de Querétaro (México) de 1917 y de Weimar (Alemania) de 1919. Los dos últimos textos constitucionales se instituyeron en fuente de inspiración de las Cartas que van a contener las reivindicaciones económicas, sociales y culturales dentro del Sistema de Derechos Fundamentales, hasta hacerlos indispensables en las Constituciones modernas. En este panorama descrito, se ubican las Constituciones Políticas del Perú de 1920 y 1933.

Los derechos fundamentales pasan a ser con mayor fuerza un elemento insustituible de la democracia, sobre todo con la Constitución de Weimar y después de la Segunda Guerra Mundial, cuando se consagran en la Constitución de Francia de 1946, en la italiana de 1947, en la Ley Fundamental de la República Federal Alemana de 1949, en la Constitución de Grecia de 1975, en la Constitución de Portugal de 1976 y en la Constitución de España de 1978. Esta tendencia está también presente en las Constituciones latinoamericanas, entre las cuales tenemos la Constitución Política del Perú de 1979 y la de 1993, aun cuando esta última sanciona graves retrocesos.

En este proceso, las numerosas Cartas Constitucionales fueron estableciendo un Sistema de Derechos Fundamentales que conjuga los derechos individuales con los derechos económicos, sociales y culturales, afirmándose la Constitución en un nexo de interdependencia entre el Estado de Derecho y los derechos fundamentales, tal como lo señala Gregorio Peces-Barba, cuando dice que "los derechos económicos, sociales y culturales suponen un derecho de crédito frente al Estado para exigir una acción positiva del mismo, lo que solamente es parcialmente cierto; mientras que los derechos civiles y políticos suponen la organización y la garantía, por parte del Derecho, de un ámbito de autonomía para sus titulares, lo que también es solo parcialmente cierto...". ${ }^{3}$

Las normas que sancionan el estatuto de los derechos fundamentales, junto a aquellas que consagran la forma de Estado y las que establecen el sistema económico, son las decisivas para definir el modelo constitucional de sociedad, sin que quepa considerar estas tres cuestiones como compartimentos estancos, habida cuenta de su inescindible correlación.." Con la Carta

2 La tesis que identifica los derechos económicos, sociales y culturales con los derechos humanos de segunda generación, es decir, con aquellos derechos que comenzaron a ser incorporados a los textos constitucionales después de producirse la crisis de los derechos liberales clásicos.

3 Gregorio Peces-Barba, Reflexiones sobre los derechos económicos, sociales y culturales, Universidad de Murcia, 1981, p. 55.

Antonio E. Pérez Luño, Los derechos fundamentales, Madrid, Tecnos, 1991, p.19. 
de las Naciones Unidas de 1946, con la Declaración Universal de los Derechos Humanos de 1948, con el Pacto Internacional de Derechos Civiles y Políticos y el Pacto Internacional de Derechos Económicos, Sociales y Culturales, ambos de 1966, se concreta la universalización e internacionalización de los derechos humanos.

Consecuentemente, se puede sustentar que la positivización de los derechos humanos en casi todas las Constituciones de los países del mundo ha generado un importante "Sistema de Protección Constitucional de los Derechos Fundamentales", que hoy por hoy cumple una función sustantiva para la legitimidad y estabilidad de todo sistema democrático, pues "sin derechos humanos no hay democracia, y sin democracia no hay derechos humanos".

Esta evolución conceptual de los derechos humanos y su vinculación íntima con la idea democrática han representando una lucha permanente de los seres humanos y seguirán representando en el presente y en el futuro la forma única de buscar mejores condiciones de vida de los seres humanos. En este proceso de evolución, vemos que el concepto de los derechos humanos que expresan la indisolubilidad de los derechos civiles, políticos con los derechos económicos, sociales y culturales va expandiéndose con el incremento del derecho a la paz, al desarrollo, a la libre determinación de los pueblos, a un medio ambiente sano y ecológicamente equilibrado, al beneficio del patrimonio común de la humanidad, denominados "derechos de solidaridad", o "derechos de tercera generación", que son también para nosotros derechos humanos.

Emilia Bea dice: "La llamada tercera generación de derechos humanos conecta con el intento de superar la tendencia generalizada en la Edad Moderna de menosprecio a lo colectivo, en aras de una individualización que va unida al protagonismo del Estado". 5 De igual manera, Roxana Arroyo Vargas sostiene que los derechos humanos de tercera generación interesan a todos los Estados y protegen intereses que no se limitan a un Estado o un grupo de Estados, sino que afectan a la comunidad internacional en su conjunto. ${ }^{6}$

Es interesante constatar como el derecho a un medio ambiente sano y ecológicamente equilibrado ha empezado a ser incluido en las Constituciones latinoamericanas de Brasil de 1988, Colombia de 1991, Paraguay de 1992, Perú de 1993 y Argentina de 1994, junto a los derechos civiles, políticos, económicos, sociales y culturales. La constitucionalización de estos derechos se enmarca en un proceso de profundización de la conciencia democrática que requiere difundirse en la opinión pública nacional e internacional, a fin de comprender,

5 Emilia Bea, "Los derechos de las minorías nacionales: su protección internacional con especial referencia al marco europeo”. En: Derechos humanos. Concepto, fundamentos, sujetos, Madrid, Tecnos, 1992, p. 166.

6 Arroyo Vargas, Roxana. "Perspectiva histórica de los derechos humanos". En: Derechos económicos y sociales. El gran desafio de la paz regional. Doctrina sobre derechos humanos, Serie Jurídica N³, San José, Codehuca, 1993, p. 24. 
respetar y proteger estos derechos. ${ }^{7}$ Hasta aquí hemos analizado el proceso de positivización de los derechos humanos desde los derechos civiles, políticos, económicos, sociales, culturales y los llamados de tercera generación.

El reto más importante, sobre todo en América Latina, para el avance de la democracia y de los derechos humanos es llegar a eliminar las dificultades que impidan esa valoración de conciencia de los derechos humanos indisolubles, y en particular los derechos humanos de los pueblos indígenas, por ser al mismo tiempo derechos individuales y derechos colectivos, como parte de los sistemas legales nacionales e internacionales y de la práctica institucional de los Estados.

\subsection{Normatividad internacional y derechos humanos de los pueblos indígenas}

Los derechos humanos de los pueblos indígenas no configuran nuevos derechos sino reivindicaciones históricas que tienen su origen en la colonización europea del siglo XVI y en la Constitución de los Estados Nacionales, cuya estructura jurídico- política ha significado la negación de la pluralidad y la homogeneización de las diferencias.

Es necesario tener presente que desde la Carta de las Naciones Unidas y la Declaración Universal de los Derechos Humanos, en la normatividad internacional se ha desarrollado un Sistema de Protección Internacional de los Derechos Universales de todo ser humano sin distinción, que comprende los derechos individuales y sociales de los pueblos indígenas en su condición de personas pertenecientes a la comunidad social; no obstante, los pueblos indígenas demandan ser reconocidos como sujetos de derechos individuales y colectivos.

El primer instrumento jurídico internacional sobre los derechos individuales y colectivos de los pueblos indígenas del mundo ha sido el Convenio 107 sobre Poblaciones Indígenas y Tribales de la OIT de 1957, que en el Perú fue aprobado mediante Resolución Legislativa 13467 de 1960. Este convenio respondió a la política paternalista, integracionista y asimilacionista de su tiempo; pero, pese a ello, dentro del Sistema de Protección Internacional de los Derechos Humanos fue un precedente jurídico fundamental al reconocer los derechos de los pueblos indígenas como entidades colectivas.

El 27 de junio de 1989, la Conferencia General de la Organización del Trabajo adoptó el Convenio 169 sobre Pueblos Indígenas y Tribales en Países Independientes. Este convenio adopta nuevas normas internacionales que respondan a las aspiraciones de los pueblos indígenas y tribales que en muchas partes del mundo no pueden gozar de los derechos fundamentales en el mismo grado que el resto de la población de los Estados en que viven.

7 Ara Pinilla, Ignacio, Op.cit., pp.160-161. 
Hasta el momento, este convenio constituye el instrumento jurídico internacional más avanzado sobre el reconocimiento y protección de los derechos preexistentes de los pueblos indígenas y tribales del mundo. A partir de ello, dentro del Sistema de Protección Internacional de los Derechos Humanos se empieza a configurar un marco normativo que conjuga los derechos e intereses de los pueblos indígenas con los derechos e intereses de los Estados, camino hacia el establecimiento de una nueva relación Estado- pueblos indígenas.

- Entre los principios básicos del Convenio 169, están:

- El reconocimiento de la existencia perdurable de los pueblos indígenas.

- El reconocimiento del derecho a la autoidentificación indígena.

- El reconocimiento de la capacidad de los pueblos indígenas para asumir el control de sus propias instituciones, formas de vida y desarrollo económico.

- El reconocimiento de la contribución de los pueblos indígenas a la diversidad cultural, a la armonía social y ecológica de la humanidad y a la cooperación y comprensión internacional.

El Congreso de la República del Perú ha aprobado el Convenio 169 de la OIT el 2 de diciembre de 1993, ratificado por el Poder Ejecutivo el 17 de enero de 1994 y registrado ante la OIT el 2 de febrero del mismo año. En la actualidad, en el mundo se abre el debate sobre "la interculturalidad de los pueblos que exige el respeto y gestión de la diferencia, y ver las diferentes formas utilizadas por las culturas para llegar al conocimiento. La interculturalidad es iniciar el prometido diálogo de saberes. En la historia de los derechos humanos actúan, además de la razón y la ciencia, otros referentes mágicos y míticos que siempre se han dejado de lado" ${ }^{8}$ Los derechos humanos de los pueblos indígenas pasan por el respeto de la interculturalidad como el reconocimiento de todos los saberes y todas las racionalidades.

Del hecho plural de lo jurídico, como común denominador de todos los pensamientos y todas las culturas, no queda más que reconocer la pluralidad de hechos fundantes de los derechos humanos, y no de una sola tradición cultural. Carlos Pérez Ruiz señala: "Los esfuerzos actuales en busca de una fundamentación mediante la teoría de los derechos humanos, la de los principios jurídicos, las teorías del consenso, de las necesidades básicas... algo en suma a lo que atenerse, algo fijo en lo que fundamentar la toma de decisiones (...) cualquier intento de fundamentación permanente tropezará una y otra vez, nunca la misma vez, con la primera regla metodológica, que presenta la evidencia de lo real".?

8 Conferencia dictada por Luis Alfonso Fajardo Sánchez. Doctor en Derecho por la Universidad Carlos III de Madrid y Doctor en Sociología Jurídica por la Universidad Complutense de Madrid.

9 Pérez Ruiz, Carlos, La construcción social del Derecho, Sevilla, España, Universidad de Sevilla,1996, p. 15. 
Hablar de derechos humanos tomando solo la historia de Occidente es una de las formas de prejuicio: Ello no permite que este encuentro que propone Bobbio en su última obra, Elogio a la Templanza, sea posible: las verdades absolutas no construyen sociedades libres. Aunque el profesor Bobbio defiende una educación universalista y democrática inspirada en principios universales como la libertad, la justicia, el respeto por el otro, la tolerancia, la no violencia, deja abierta la posibilidad para que sea reconocida la diferencia, y lo diferente tiene su historia diferente. A manera de ejemplo, la sociedad Inca se ha regido desde siglos antes de la llegada de los europeos por principios que han sido construidos a partir de su cotidianidad y su historia.

En varias declaraciones de diferentes países sobre derechos humanos está presente la interculturalidad; así tenemos:

- La Carta Africana de los Derechos Humanos.

- La Carta Árabe de Derechos Humanos.

- La Carta Europea de los Derechos Humanos.

- La Declaración Americana de Derechos Humanos.

- La Carta de la ONU.

Finalmente, creemos que defender, respetar y proteger los derechos humanos de los pueblos indígenas es reconstruir sus economías, su seguridad y recomposición territorial, sus recursos y conocimientos, además de proceder a la reparación histórica de las vejaciones a las que han sido sometidos, recuperar para ellos una digna calidad de vida y respetar sus opciones en cuanto se refiera a las medidas que puedan afectarles. Hablamos de sus derechos económicos, sociales y culturales, en torno a los que gira su desarrollo y superación.

\section{SITUACIÓN ACTUAL DE LOS DERECHOS ECONÓMICOS SOCIALES Y CULTURALES DE LOS PUEBLOS INDÍGENAS}

\subsection{A nivel internacional}

Los derechos de los pueblos indígenas, al igual que los derechos de todos los ciudadanos del mundo, están enunciados en diversos tratados y declaraciones regionales e internacionales; es decir, todo el conjunto de derechos recogidos en los instrumentos internacionales de derechos humanos son aplicables a las comunidades indígenas. Así tenemos la Declaración Universal de Derechos Humanos, el Pacto Internacional de Derechos Civiles y Políticos, el Pacto Internacional de Derechos Económicos, Sociales y Culturales, la Convención Internacional sobre la Eliminación de todas las Formas de Discriminación Racial, la Convención contra la 
Tortura y Otros Tratos o Penas Crueles, Inhumanos o Degradantes, la Declaración Americana de los Derechos y Deberes del Hombre, la Convención Americana sobre Derechos Humanos, entre otros.

De igual manera, tenemos el Convenio Internacional 169 de la OIT, el Convenio sobre Diversidad Biológica, los acuerdos de la Organización Internacional de Maderas Tropicales (OIMT), de la Comunidad de Desarrollo Sustentable de la ONU, así como los acuerdos políticos y técnicos de la Conferencia de las Naciones Unidas sobre Medio Ambiente y Desarrollo referidos a derechos indígenas, tales como La Agenda 21, La Declaración de Principios sobre Bosques, y finalmente la Declaración de Río sobre el Medio Ambiente y Desarrollo, cuyo principio 22 está referido a los derechos de los pueblos indígenas.

Los aspectos centrales de lucha de los movimientos indígenas en el mundo y Latinoamérica giran especialmente sobre sus territorios, el respeto y reconocimiento cultural, la participación en la planificación de políticas, leyes, programas, estrategias, el derecho al desarrollo, el derecho al respeto y protección de sus conocimientos y prácticas culturales, entre otros. Desde hace tres décadas, aproximadamente, el fortalecimiento de estas luchas se ha expresado en el fortalecimiento de sus organizaciones, cada vez más crecientes en todos los niveles locales, regionales, nacionales e internacionales.

Los pueblos indígenas han desarrollado un conjunto de demandas en relación con el Estado Nacional del cual forman parte, con prioridad en los siguientes aspectos:

\section{- TERRITORIOS}

Los pueblos indígenas en sus demandas tratan de asegurar los medios básicos de vida, desde la seguridad para sus parcelas de cultivo hasta los derechos territoriales.

\section{- PARTICIPACIÓN EN EL DESARROLLO ECONÓMICO Y MATERIAL}

Los pueblos indígenas luchan para asegurar su participación en los beneficios del desarrollo nacional, así como para mantener sus propias formas de vida y prácticas culturales. Sus demandas apuntan a ampliar sus formas de participación, corresponsabilidad y autogestión en programas y políticas técnico-financieros, así como en el manejo de recursos.

\section{- DESARRollo CUltural}

Sus demandas están orientadas al derecho de usar su lengua, religión, prácticas médicas y saberes tradicionales, así como de organizar sus propios procesos educativos y comunicación social. 


\section{- JUSTICIA}

Los pueblos indígenas buscan a través de sus organizaciones que sus derechos, que siempre han sido ajenos a ellos, tanto en la justicia como en la defensa de los individuos, se incorporen como leyes y normas en las legislaciones de sus países. Mucho más en relación con los derechos humanos, que hoy constituyen un tema de primer orden.

\section{- AUTONOMÍA}

Los defensores de los derechos humanos de los pueblos indígenas consideran que no será posible el respeto de todos los derechos vinculados a sus bienes territoriales, medio natural, recursos económicos y patrimonio cultural si no logran su autonomía. Esta autonomía no implica una voluntad de secesión respecto de los Estados, pero se plantea un reordenamiento de la estructura legal que asegure a los pueblos indígenas su representación en la toma de decisiones y en la formulación de las políticas que los afectan.

La VIII reunión de la Conferencia Iberoamericana de Comisiones Nacionales para la conmemoración del descubrimiento de América, realizada en Guatemala en 1989, fue un paso importante como propuesta referida a los cambios en las políticas indigenistas y su institucionalización en la legislación de los Estados Parte, como parte de la modernización de los Estados y como resultado de la acción de los movimientos indígenas en su nueva situación nacional frente a sus derechos económicos, sociales y culturales.

Estas transformaciones suponen tres pasos fundamentales:

1. El cambio de la concepción de integrar lo indígena por la noción de reconocer la especificidad indígena dentro de la pluralidad de la nación.

2. El cambio de una estrategia de asistencia del Estado a las necesidades indígenas, por una de la participación directa de los indígenas en las decisiones que les conciernen.

3. El cambio de una actitud paternalista por una de diálogo y participación activa de los mismos indígenas.

Si bien es cierto que las demandas de los pueblos indígenas en el plano internacional son cada vez más crecientes, a la par de estos avances, se siguen violando sus derechos económicos, sociales y culturales en el mundo y en América Latina. Se cree, por ejemplo, que en El Salvador, en 1932, murieron unas 30000 personas, muchas de las cuales fueron indígenas. Las Naciones Unidas, desde su funcionamiento, se han ocupado poco de las poblaciones indígenas en el mundo. 
Las circunstancias en las que los pueblos indígenas se convierten en víctimas de violaciones de derechos humanos varían considerablemente a lo largo de todo el territorio americano. En México y Ecuador, los indígenas enconados en disputas sobre tierras han sufrido frecuentes detenciones y torturas y algunos han sido ejecutados extrajudicialmente. Cabe resaltar las luchas últimas del movimiento indígena ecuatoriano.

En los Estados Unidos existen indígenas que se encuentran condenados a muerte. En el caso del Perú, las comunidades indígenas estuvieron atrapadas durante una década en un conflicto entre las fuerzas del Estado y los grupos alzados en armas.

En toda América, los activistas por los derechos de los indígenas han pagado este compromiso con la libertad y la vida. Algunos pueblos se han convertido en víctimas por denunciar públicamente los abusos sufridos por sus comunidades, o por tomar parte activa en grupos que protestaban frente a tales abusos. Otros han sido seleccionados por su pertenencia a sindicatos y organizaciones políticas. En casi toda América, la discriminación ha postergado socialmente a los pueblos indígenas.

En muchos casos, la evangelización o la asimilación han debilitado su personalidad cultural. Hoy en día, los pueblos indígenas sufren a menudo una situación de desventaja económica y marginación en las sociedades en las que viven, debido a factores geográficos, culturales y lingüísticos. Además, esta discriminación las hace con frecuencia más vulnerables al abuso que otros sectores de la sociedad. Existen teóricamente disposiciones tanto en el Derecho nacional como en el internacional que protegen a los pueblos indígenas. En diferentes países, muchas veces es directa la participación de los agentes del Estado en violaciones de los derechos humanos. Todavía es lenta y escasa la intervención judicial.

Como consecuencia de este consistente despliegue de esfuerzos, algunos gobiernos de América, como algunos organismos internacionales, vienen dedicando en estos últimos años una atención creciente a las cuestiones indígenas. Esta preocupación en el continente americano se ha extendido fuera de la región. Por ejemplo, en la Organización de las Naciones Unidas, desde 1982, han venido examinando la evolución de los asuntos que afectan los derechos de los pueblos indígenas. Producto de esto es la dación de normas relativas a estos derechos.

La creciente preocupación internacional por el medio ambiente coincide muchas veces con los usos tradicionales de los indígenas, y esto ha supuesto tener a los pueblos indígenas como nuevos aliados en el plano nacional e internacional. Dentro de los pueblos indígenas, los niños, las mujeres embarazadas, los ancianos, los disminuidos mentales o físicos y los grupos aislados son los más vulnerados en sus derechos. 
En varios países de América Latina existen grupos aislados que han tenido poco o ningún contacto con la sociedad no indígena, o que han entrado en contacto recientemente. Estos grupos son vulnerados en sus derechos, sobre todo respecto de sus tierras. Brasil, Paraguay y Bolivia son países donde se han registrado abusos contra indígenas aislados. Algunas de las causas son las actividades de la industria maderera y pesquera.

Los Estados Parte, los gobiernos, están obligados a defender los derechos humanos de los pueblos indígenas.

\subsection{Los derechos económicos, sociales y culturales de los pueblos indígenas del Perú}

Ante la crisis de legitimidad de las democracias, la inestabilidad económica, la inseguridad jurídica, la falta de mecanismos de participación directa de los ciudadanos en las decisiones políticas del Estado y el desplazamiento de los derechos sociales hacia simples expectativas formales, los países del Tercer Mundo han optado por poner en marcha un programa de reformas en que el Estado solo se concentre en el diseño de las políticas generales y la atención de los servicios sociales básicos, entregando al sector privado la responsabilidad del desarrollo, el mismo que debe desenvolverse dentro de un ambiente adecuado de competencia y de mercado.

Evidentemente, no se puede negar la crisis de legitimidad del Estado Social, tampoco desconocer que asistimos a un mundo cada vez más globalizado, pero creemos que el gran desafío es cómo conseguir ser una nación competitiva sin renunciar a nuestra esencia pluriétnica y cultural, cómo conseguir que el Perú sea una nación competitiva respetando los aspectos sociales, culturales y ambientales asociados al desarrollo; y específicamente, cómo armonizar los derechos humanos de los pueblos indígenas, la protección del medio ambiente y el desarrollo sostenible. A partir de 1990, en la sociedad peruana se han impuesto las reformas del Estado y la reinserción financiera en la comunidad internacional. Prima el concepto de que "hay cosas que el individuo hace mejor que el Estado", y aplica todo el proceso de privatización.

En este contexto se inscribe la Constitución Política de 1993. Entre los aspectos más relevantes de esta Constitución está el reconocimiento de la pluralidad étnica y cultural de la nación. Así, en su artículo $2^{\circ}$ inciso 19 establece que "el Estado reconoce y protege la pluralidad étnica y cultural de la Nación”. Por consiguiente, al igual que en la Constitución de 1979, el Estado debe respetar el derecho de las comunidades campesinas y nativas a su realidad étnica y cultural, proteger su derecho a gozar de un ambiente equilibrado y adecuado al desarrollo de su vida, fomentar la educación bilingüe e intercultural en las zonas donde están ubicadas, preservar sus manifestaciones culturales y lingüísticas, resguardar su autonomía organizativa, económica y administrativa, garantizar su derecho de propiedad comunal sobre sus tierras 
y salvaguardar la vigencia de su derecho consuetudinario. Sin ello no será posible el goce pleno de sus derechos fundamentales civiles, políticos, económicos, sociales y culturales, ni su desarrollo sostenible.

En el artículo 89 de la Constitución de 1993, se establece que "las comunidades son autónomas en la libre disposición de sus tierras", quebrando de esta manera una importante tradición constitucional peruana de protección de la integridad de la propiedad territorial de las comunidades indígenas, pues limita, por un lado, los principios de inalienabilidad e inembargabilidad y, por el otro, relativiza el principio de imprescriptibilidad de las tierras comunales. Específicamente, con relación a la Constitución de 1979, es un retroceso porque reduce la función social de la tierra, elimina la preferencia de la adjudicación a los campesinos sin tierra, y elimina el deber del Estado de promover el desarrollo integral de las comunidades campesinas y nativas.

La Ley de Promoción de las Inversiones Privadas en las Tierras del Territorio Nacional y de las Comunidades Campesinas y Nativas (Ley 26505 de 1995 "Ley de Tierras") consolida la liberalización de la propiedad comunal de las tierras o mercado de tierras, en abierta contravención de las disposiciones del Convenio 169 de la OIT, pues se incorporan las tierras de las comunidades campesinas y nativas al mercado de la oferta y demanda para su venta, arrendamiento, otorgamiento en garantía de obligaciones u otros casos.

La ley 26505, lejos de promover el desarrollo de los pueblos indígenas, acaba limitándolo porque no otorga seguridad jurídica a las comunidades campesinas y nativas sobre la propiedad de sus tierras comunales, base principal de su existencia y desarrollo. Si bien es cierto que la legislación peruana vigente muestra algunos avances significativos con relación a la protección de los derechos económicos, sociales y culturales de los pueblos indígenas, mediante la ratificación del Convenio 169 de la OIT, el Convenio sobre Diversidad Biológica, la Agenda 21 y el Acuerdo Internacional sobre Maderas Tropicales, todavía está integrada por un conjunto de disposiciones que corresponden a diferentes períodos de gobierno y responden a políticas también distintas.

Por otra parte, en los últimos años, el Estado ha aprobado y promulgado un conjunto de leyes que directa o indirectamente involucran derechos de las comunidades nativas, como el Código del Medio Ambiente y los Recursos Naturales de 1990, la Ley Marco para el Crecimiento de la Inversión Privada de 1991, la Ley de Promoción de las Inversiones en el Sector Agrario de 1991, la Ley Orgánica de Hidrocarburos de 1993, la Ley de Tierras de 1995, La Ley Orgánica para el Aprovechamiento Sostenible de los Recursos Naturales de 1997, la Ley sobre la Conservación y Aprovechamiento Sostenible de la Diversidad Biológica de 1997 y la Ley de Áreas Naturales Protegidas de 1997. Un aspecto común de tales disposiciones 
es que abordan los derechos de las comunidades nativas de manera sectorizada, dispersa y aislada, sin que se cumpla hasta el momento con el mandato constitucional de elaborar y aprobar una "Ley Marco sobre los Derechos Indígenas".

A esta circunstancia se añade la Ley de Organización y Funciones del Ministerio de Promoción de la Mujer y del Desarrollo Humano, habiendo sido disuelto el Instituto Indigenista Peruano y convertido en una Unidad de la Oficina de Desarrollo Productivo de la Gerencia de Desarrollo Humano. Igualmente, se constata que aún subsiste una práctica constante que privilegia el incumplimiento de las leyes, acompañada de una falta de institucionalidad para vigilar el cumplimiento de las mismas. Esta falta de legalidad termina por colocar a los pueblos indígenas en una posición cada vez más vulnerable para asegurar el respeto de sus derechos individuales y colectivos. A esto hay que añadir los 23 contratos aproximados de licencia para la exploración y/o explotación de hidrocarburos suscritos, respecto de lotes que en muchos casos se superponen a los territorios tradicionalmente ocupados por los pueblos indígenas de la Amazonía.

A la fecha se ha cumplido con adecuar la legislación nacional a los principios y contenido de las normas del Convenio 169 de la OIT, mediante la "Ley de Consulta Previa", que entre otros temas establece los procedimientos apropiados de consulta y participación de los pueblos indígenas en las actividades de explotación de los recursos naturales existentes en sus territorios tradicionales. ${ }^{10}$ Dicho en otros términos, se trata de una Ley que garantiza la participación indígena en el control de los impactos ambientales y socioculturales, en los beneficios que se generen y que aseguren una indemnización justa en caso de daños.

En las actuales condiciones, sin duda corresponde a los propios pueblos indígenas, en atención a sus intereses y prioridades, decidir libre y autónomamente cómo conducen su desarrollo económico, social y cultural; qué mecanismos utilizan en su relación con el Estado y el sector privado para participar en los beneficios del desarrollo; y cuál es la magnitud de los cambios que aspiran para sus pueblos, pues como toda cultura no están obligados a permanecer estáticos en sus estructuras y tradiciones, sino que tienen derecho a dirigir su vida y su futuro sin que esto signifique renunciar a los principios que forman parte de su identidad étnica y cultural. Estos hechos hasta aquí descritos constituyen solamente una muestra de la situación actual de los derechos indígenas en el Perú, que deben despertar el interés del Estado y de la sociedad nacional por comprender mejor los problemas que afrontan los pueblos indígenas, pues en la mayor parte de los casos la causa de los conflictos está en la indiferencia.

10 El 6 de septiembre de 2011, el Congreso de la República reconoce el derecho de los pueblos indígenas a ser consultados previamente con respecto a medidas legislativas o administrativas, y a planes, programas y proyectos de desarrollo que puedan afectar sus derechos. 
Es necesario, pues, un cambio de actitud desde el Estado, la sociedad y los pueblos indígenas para establecer nuevas formas de entendimiento, aceptación y tolerancia.

La ley establece, entre otros aspectos significativos, que la finalidad de realizar esta consulta es alcanzar un acuerdo o consentimiento entre el Estado y los pueblos indígenas u originarios a través de un diálogo intercultural que garantice su inclusión en los procesos de toma de decisión del Estado y la adopción de medidas respetuosas de sus derechos colectivos; que el contenido de la ley se debe interpretar de conformidad con las obligaciones consagradas en el Convenio 169 de la OIT, ratificado por el Perú; y que los principios rectores del derecho a la consulta incluyan los de oportunidad, interculturalidad, buena fe, flexibilidad, plazo razonable, ausencia de coacción o condicionamiento, e información oportuna. Asimismo, la CIDH considera importante que se le dé una amplia difusión a esta Ley y que en el proceso de reglamentación y aplicación de la misma se continúe profundizando en la implementación de los estándares jurídicos fijados por el Sistema Interamericano de Derechos Humanos sobre los derechos a la consulta y al consentimiento previos, de manera libre e informada. Se requiere profundizar el reconocimiento y garantía de sus derechos y libertades fundamentales en el marco del Derecho Internacional. En este sentido, el antropólogo Rodolfo Stavenhagen afirma: "La violación de los derechos humanos de los grupos indígenas no se manifiesta solamente por las carencias de orden material y los procesos de despojo y explotación de los que son víctimas, que han sido extensamente documentados (...), sino también porque se les ha negado sistemáticamente la posibilidad de poder conservar y desarrollar sus propias culturas..." ${ }^{11}$ Y refuerza esta afirmación agregando: "Es cada vez más evidente que la vigencia y efectividad de los derechos humanos individuales universales entre los pueblos indígenas pasa por el reconocimiento de sus derechos étnicos colectivos." 12

Desde este punto de vista, en un mundo cada vez más interdependiente y globalizado, la interacción entre el Derecho Internacional de los derechos humanos y el Derecho Interno de los Estados ha de cumplir un rol fundamental en el avance normativo y práctico del reconocimiento y protección de los derechos humanos individuales y colectivos de los pueblos indígenas, pues el fenómeno de la universalización e internalización de los derechos humanos no es un proceso concluido sino un asunto abierto al futuro, en la medida que existen amplios sectores de la población mundial que no son aún sujetos reales de los derechos humanos; por tanto, su materialización es todavía un desafío para la humanidad.

11 Stavenhagen, Rodolfo, Derecho indígena y derechos humanos en América Latina, México, El Colegio de México y el IIDH,1988, p .9.

12 Stavenhagen, Rodolfo, "Derechos Humanos y Derechos Indios", en: La visión india. Tierra, cultura, lengua, derechos bumanos, Leiden, Holanda, Musiro, 1989. p. 16. 


\section{PERSPECTIVAS DE LOS DERECHOS ECONÓMICOS, SOCIALES Y CULTURALES DE LOS PUEBLOS INDÍGENAS}

El período moderno ha estado expresado por la homogeneización de las diferencias respetando ciertas peculiaridades de los pueblos indígenas hasta lograr su integración. De este modo, el período postmoderno, en este siglo que se inicia, debe significar la articulación de las diferencias, de la diversidad, de las autonomías y del pluralismo jurídico- político mediante una nueva relación Estado-sociedad-pueblos indígenas.

La realidad sociopolítica de los países de América y el mundo muestra más de una vez y en forma creciente los límites del Estado moderno, pero también la afirmación del concepto de los derechos humanos como herencia de la humanidad; es claro que esta circunstancia impone la necesidad de un mayor grado de compromiso entre todos los sectores sociales nacionales e internacionales, para avanzar hacia el reconocimiento efectivo de los derechos humanos de los pueblos indígenas en el mundo y en el Perú.

En definitiva, se debe dejar de lado todos aquellos paradigmas como la soberanía de los Estados, seguridad nacional, unidad nacional, Derecho positivo, que hasta hoy no han permitido una incorporación real de los valores de los pueblos indígenas en el concepto y contenido de los sistemas legales nacionales e internacionales y en la práctica institucional de los Estados. En consecuencia, es necesario apostar por un diálogo intercultural entre los Estados, la comunidad internacional y los pueblos indígenas, lo que significa también apostar por la construcción de nuevas relaciones humanas.

Al respecto, existen avances en los grupos de trabajo de los organismos internacionales, pero también en los Estados nacionales, como se ve en las Constituciones de Guatemala, Nicaragua, Colombia, Perú, México y Bolivia, donde se reconoce la composición multiétnica de las naciones y el respeto hacia estas.

Sin embargo, se requiere una mayor conciencia nacional y democrática para legalizar la naturaleza plural de las sociedades latinoamericanas dentro de la estructura jurídica y política de los Estados. El problema indígena no es solo de los pueblos indígenas, es de la sociedad global, de la comunidad internacional en su conjunto; por tanto, es indispensable repensar la organización del Estado camino hacia el reconocimiento no solo de la pluralidad cultural sino también de la pluralidad política y jurídica en la estructura y funcionamiento de los Estados.

Los pueblos indígenas de Latinoamérica han empezado a construir su futuro a través del dialogo y la negociación de importantes acuerdos, compromisos y propuestas con los Estados. Esto es un llamado a toda la comunidad internacional para coadyuvar en el avance no solo del establecimiento de nuevas formas de relación entre el Estado, la sociedad y los 
pueblos indígenas, sino fundamentalmente en la afirmación del valor del reconocimiento de la interculturalidad, y sobre esta base, promover el respeto y la solidaridad como condiciones necesarias para el progreso de la democracia y de los derechos humanos en general, y de los derechos humanos de los pueblos indígenas en particular.

\section{REFERENCIAS BIBLIOGRÁFICAS}

1. Ara Pinilla, Ignacio, Las transformaciones de los derechos humanos, Madrid, Tecnos, 1990.

2. Arroyo Vargas, Roxana, "Perspectiva histórica de los derechos humanos". Serie Jurídica N³, San José, Codehuca, 1993.

3. Bea, Emilia, Los derechos de las minorias nacionales: su protección internacional con especial referencia al marco europeo, Madrid, Tecnos, 1992.

4. Comisión Andina de Juristas, Cultura y justicia indígenas ante la violencia, Lima, 1988.

5. Fajardo Sánchez, Luis Alfonso, "Interculturalismo y derechos humanos: vía múltiple para el respeto de la dignidad humana", conferencia dictada en el Centro Bartolomé de las Casas, Cusco, 2000.

6. Gager, Julio, Las conquistas de las naciones indigenas en la Asamblea Nacional Constituyente del Brasil, Lima, CIPA, 1988.

7. Pérez Luño, Antonio E., Los derechos fundamentales, Madrid, Tecnos, 1991.

8. Pérez Ruiz, Carlos, La construcción social del Derecho, Sevilla, España, Universidad de Sevilla, 1996.

9. Secretaría Permanente de la Conferencia Iberoamericana de Comisiones para la Conmemoración del Quinto Centenario del Descubrimiento de América. Encuentro de dos Mundos. (Madrid), "Presencia y Significación de los Pueblos Indígenas de América", Madrid, 1989.

10. Stavenhagen, Rodolfo, Derecho indígena y derechos humanos en América Latina, México, El Colegio de México y el IIDH, 1988.

11. Stavenhagen, Rodolfo, Derechos humanos y derechos indios, Leiden, Holanda, Musiro, 1989.

12. Valdivia Dounce, Teresa, Derechos indigenas, mujeres y discriminación en América Latina, Lima, CIPA, 1987. 